\title{
Intercomparison of soil pore water extraction methods for stable
}

\section{isotope analysis}

\section{Natalie Orlowski ${ }^{\mathrm{a}, \mathrm{b}^{*}}$, Dyan L. Pratt ${ }^{\mathrm{c}}$ and Jeffrey J. McDonnell ${ }^{\mathrm{a}, \mathrm{d}}$}

[a]\{Global Institute for Water Security, School of Environment and Sustainability, University

of Saskatchewan, 11 Innovation Boulevard, Saskatoon, SK S7N 3H5, Canada\}

[b]\{Institute for Landscape Ecology and Resources Management (ILR), Research Centre for BioSystems, Land Use and Nutrition (IFZ), Justus Liebig University Giessen, Heinrich-BuffRing 26-32, 35392 Giessen, Germany

[c] \{Global Institute for Water Security, Civil and Geological Engineering, University of Saskatchewan, 57 Campus Drive, Saskatoon, SK S7N 5A9, Canada\}

[d] $\{$ School of Geoscience, University of Aberdeen, Meston Building, Old Aberdeen, AB24 3UE Aberdeen, United Kingdom

*Correspondence to: Natalie Orlowski, Global Institute for Water Security, School of Environment and Sustainability, University of Saskatchewan, 11 Innovation Boulevard, Saskatoon SK S7N 3H5, Canada. Email: Natalie.Orlowski@usask.ca

This article has been accepted for publication and undergone full peer review but has not been through the copyediting, typesetting, pagination and proofreading process which may lead to differences between this version and the Version of Record. Please cite this article as doi: $10.1002 /$ hyp. 10870 


\section{Abstract}

Measurements of $\delta^{2} \mathrm{H}$ and $\delta^{18} \mathrm{O}$ composition of pore waters in saturated and unsaturated soil samples are routinely performed in hydrological studies. A variety of in-situ and lab-based pore water extraction methods for the analysis of the stable isotopes of water now exist. While some have been used for decades (e.g. cryogenic vacuum extraction) others are relatively new, such as direct vapor equilibration or the microwave extraction technique. Despite their broad range of application, a formal and comprehensive intercomparison of soil water extraction methods for stable isotope analysis is lacking and long overdue. Here we present an intercomparison among five commonly used lab-based pore water extraction techniques (high pressure mechanical squeezing, centrifugation, direct vapor equilibration, microwave extraction, and cryogenic extraction). We applied these extraction methods to two physicochemically different soil types that were dried and rewetted with water of known isotopic composition at three different water contents. Our results showed that the extraction approach can have a significant effect on pore water isotopic composition as all methods exhibited significant deviations from the spiked reference water, depending secondarily on the soil type and soil water content. Most pronounced, cryogenic water extraction showed large deviations from the spiked reference water, whereas mechanical squeezing and centrifugation provided results closest to the spiked water for both soil types. We also compared results for each extraction method - where liquid water was obtained - on both an OA-ICOS and IRMS. Differences between these two analytical instruments were negligible for these organic compound-free waters. We suggest that users of soil water extraction approaches carefully choose an extraction technique that is suitable for the specific research question, adapted to the dominant soil type and water content of the study.

This article is protected by copyright. All rights reserved. 
Key words: soil water extraction; stable water isotope; cryogenic vacuum extraction; centrifugation; mechanical squeezing; direct vapor equilibration

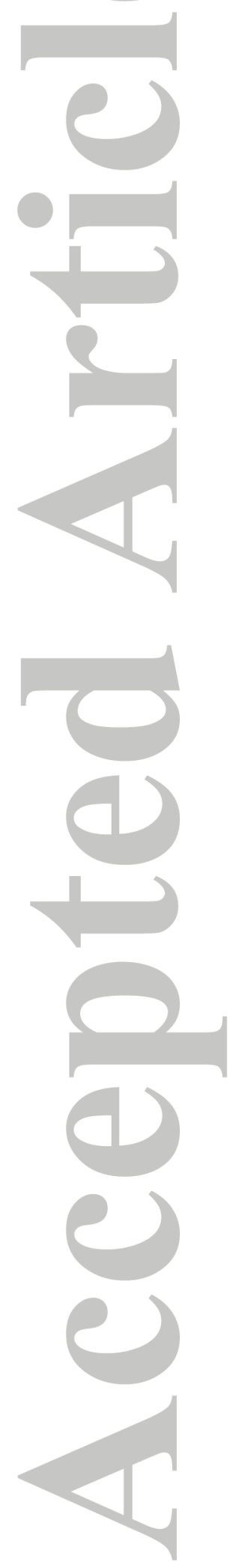

This article is protected by copyright. All rights reserved. 


\section{INTRODUCTION}

Pore water extracted from soils for isotope analysis is now used extensively in hydrological process investigations. Such approaches are applied over a broad range of disciplines to characterize mixing processes in the soil (Gaj et al., 2016; Orlowski et al., 2015; Thomas et al., 2013), investigate water flow paths at the hillslope scale (Garvelmann et al., 2012; Mueller et al., 2014; Vogel et al., 2010; Windhorst et al., 2014), estimate transit times in soil profiles (Sprenger et al., 2015b; Stumpp et al., 2009; Timbe et al., 2014), partition evaporation and transpiration fluxes (Dubbert et al., 2014; Rothfuss et al., 2010; Wang et al., 2012), study water resource competition of plants (Meißner et al., 2012; Williams and Ehleringer, 2000), and to derive community water-use patterns or zones of root activity in soils (Isaac and Anglaaere, 2013; Liu et al., 2011). The capability to extract isotopically unfractionated water from soils is fundamental to all these studies and is still not solved (Munksgaard et al., 2014; Orlowski et al., 2016).

To analyze the isotopic composition of soil water, a water extraction method is required. Several extraction methods have been developed and can be categorized into laboratory- and field-based methods. Further, soil water isotopic composition can be determined via direct equilibration techniques. Laboratory methods include: azeotropic distillation (Revesz and Woods, 1990; Thorburn et al., 1993), microdistillation (Kendall and Coplen, 1985), mechanical squeezing (Böttcher et al., 1997; Wershaw et al., 1966; White et al., 1985), cryogenic vacuum extraction (Dalton, 1988; Goebel and Lascano, 2012; Orlowski et al., 2013; Dawson and Ehleringer, 1993; West et al., 2006; Ehleringer et al., 2000), a modified vacuum extraction technique (Koeniger et al., 2011), centrifugation with or without immiscible heavy liquids (Mubarak and Olsen, 1976; Batley and Giles, 1979; Barrow and 
Whelan, 1980; Peters and Yakir, 2008), Picarro's Induction Module (Picarro, 2015), microwave extraction (Munksgaard et al., 2014), or the accelerated solvent extraction technique (Zhu et al., 2014). Field-based methods include: wick samplers (e.g. Landon et al., 1999; Windhorst et al., 2014), suction cups (e.g. Figueroa-Johnson et al., 2007; Landon et al., 2000; Weihermüller et al., 2005), and zero-tension lysimeters (e.g. O'Driscoll et al., 2005; Wenner et al., 1991). Equilibrium techniques include: direct liquid-water-vapor equilibrium (e.g. Wassenaar et al., 2008; Hendry et al., 2015), in situ equilibration (Gaj et al., 2016; Garvelmann et al., 2012; Rothfuss et al., 2013, 2015; Volkmann and Weiler, 2014), Hepurging (Ignatev et al., 2013), and $\mathrm{CO}_{2-}$ and $\mathrm{H}_{2}$-equilibration (Hsieh et al., 1998; Jusserand, 1980; Kelln et al., 2001; Koehler et al., 2000; McConville et al., 1999; Scrimgeour, 1995). For a detailed methodological review on the different soil water extraction methods, the reader is referred to Sprenger et al. (2015a).

Although, the sheer number and variety of soil water extraction methods and their related publications have increased dramatically in recent years, little work has been done to compare the isotopic effects of different extraction procedures on the recovered soil water. Preliminary work that has compared some of these soil water extraction techniques has suggested differences between the various approaches (Figueroa-Johnson et al., 2007; Jusserand, 1980; Kelln et al., 2001; Munksgaard et al., 2014; Sprenger et al., 2015a; Walker et al., 1994). Kelln et al. (2001) compared mechanical squeezing, centrifugation, azeotropic distillation, and a direct soil water equilibrium technique developed by Koehler et al. (2000). They showed large discrepancies between the isotopic results extracted from clay-rich soils. Similar findings were obtained by Jusserand (1980) where $\delta^{18} \mathrm{O}$ values of spiked reference water differed from the extracted values obtained through mechanical squeezing, cryogenic 
extraction, centrifugation, and a direct equilibration method. Figueroa-Johnson et al. (2007) compared centrifugation and azeotropic distillation against suction lysimeters. They found lower isotope ratios for water collected from a sandy soil by centrifugation and azeotropic distillation than when sampled via suction lysimeters. Moreover, observed discrepancies were attributed to differences in grain size distribution - in sandy soils the differences between the methods were small but became large in clayey soils (Figueroa-Johnson et al., 2007). When comparing the microwave extraction method against cryogenic extraction, Munksgaard et al. (2014) observed discrepancies between the two approaches which they attributed to incomplete cryogenic extraction. Their cryogenically extracted soil water data plotted unusually to the left of the Local Meteoric Water Line (LMWL), which suggested that absorbed water in the clay-rich soil was not fully extracted by the conventional conductive heating mode employed in the cryogenic extraction technique (Munksgaard et al., 2014; Orlowski et al., 2013). So far, it is assumed that the added water during spiking experiments becomes partly bound to soil minerals (clay hydroxyls) but is afterwards not or only partly released again during the various extraction approaches (Sprenger et al., 2015a).

Despite the work to date and the extensive application of stable water isotope analysis, no formal intercomparison of the techniques for soil water extraction and their impact on resulting soil water isotopic composition has been performed. This is a major issue in our field, as noted recently by McDonnell (2014) and Sprenger et al. (2015a). Studies are needed that explicitly explore effects of extraction techniques for mobile and immobile soil waters on the water isotope composition, especially in the ecohydrological context (McDonnell, 2014). Thus, estimates of plant water uptake depths, use of a soil water end member in hydrograph separation, or mean residence time analysis should be critically studied in light of the 
different mobilities of water in e.g. different soil types and pore spaces (Orlowski et al., 2016). The choice of sampling methods is therefore crucial for the interpretation of soil pore water stable isotope data, but a systematic comparison between the different methods was still missing (McDonnell, 2014; Sprenger et al., 2015a). Here we provide a first formal intercomparison of the five major lab-based techniques used for soil water extractions:

Cryogenic vacuum extraction, centrifugation, mechanical squeezing, direct vapor equilibrium method, and microwave extraction. We pose the null hypothesis that each extraction technique will yield the same soil water isotopic composition. We conducted the water extractions with two physicochemically different standard soils (silty sand and clayey loam), at different gravimetric water contents $(8,20$, and $30 \%)$ spiked with a known isotopic label.

\section{MATERIALS AND METHODS}

\subsection{Experimental design}

For each of the five extraction methods two physicochemically different soil types (LUFA 2.4 (clayey loam) and LUFA 2.1 (silty sand)) from the German State Research Institute for Agriculture (LUFA Speyer, 2015) (Table I) were sieved (2 mm), oven-dried (72 h, $\left.120^{\circ} \mathrm{C}\right)$, rehydrated with distilled water of known isotopic composition $\left(\delta^{2} \mathrm{H}:-59.8 \pm 1.4 \%\right.$, $\delta^{18} \mathrm{O}$ : $-8.6 \pm 0.3 \% ; \mathrm{N}=21$ ) to gravimetric water contents of 8,20 , and $30 \%$ (5 replicates per method and water content). Soils in tubes (for cryogenic extraction, centrifugation, and microwaving) were homogenized by a Vortex Genie (Scientific Industries Inc., New York, USA) and those in bags (for mechanical squeezing and direct vapor equilibration) were homogenized by hand. All samples were stored at $4^{\circ} \mathrm{C}$ for three days for equilibration of the solid and liquid phase prior to water extractions. Extraction/equilibration method specific preparations are for 
each method fully described in the following sub-sections including the extraction protocols. Pre- and post-water extraction soil sample weights as well as sample weights after an additional oven-drying $\left(24 \mathrm{~h}, 120^{\circ} \mathrm{C}\right)$ were compared to determine soil water extraction efficiency. For isotope analysis, all extracted (liquid) water samples were filtered on $0.45 \mu \mathrm{m}$ disk filters, transferred to $2 \mathrm{~mL}$ amber glass vials covered by solid silicone septa, and tightly sealed with Parafilm®.

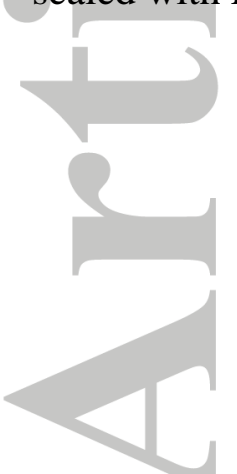

[Table I near here]

\subsection{Soil water extraction techniques and extraction parameters}

\subsubsection{Cryogenic vacuum extraction}

For cryogenic vacuum extraction, the sample material was heated $\left(>90^{\circ} \mathrm{C}\right)$ under vacuum. Thereby, water evaporated from the soil material and was subsequently caught in a (cryogenic) liquid nitrogen cold trap (Ingraham and Shadel, 1992). After defrosting, the liquid water sample was accessible for isotope analysis. We used two different cryogenic distillation systems in this study; both were extendable multi-port systems providing the possibility to extract a larger number of samples per day, simultaneously (Orlowski et al., 2013). The system developed at the Institute for Landscape Ecology and Resources Management (ILR, Giessen, DE) was a mobile setup which consisted of a vacuum manifold with six independent extraction lines, each comprising three extraction-collection units, resulting in 18 extraction slots (referred to as DE system). A detailed description and validation of this system was given in Orlowski et al. (2013). The other setup at the Global 
Institute for Water Security (GIWS, Saskatoon, CA; referred to as CA system) was very similar to the apparatus at the ILR and comprised six independent extraction lines with four extraction-collection units. 24 samples could be extracted in parallel (Orlowski et al., 2013, 2016).

For cryogenic water extraction using the DE extraction line, $20 \mathrm{~g}$ of each soil sample was placed directly into glass extraction vials. Using the CA system, $25 \mathrm{~g}$ were put into glass scintillation vials. Vials were hermetically-sealed and tops wrapped with Parafilm®. After equilibration, clayey loam samples were extracted for $240 \mathrm{~min}$ and silty sand soils for $45 \mathrm{~min}$ at a temperature of $98^{\circ} \mathrm{C}$ and a baseline pressure of $2.2 \mathrm{~Pa}$ and $0.1 \mathrm{~Pa}$ at the $\mathrm{CA}$ and $\mathrm{DE}$ line, respectively.

\subsubsection{Centrifugation}

For the centrifugation method, $40 \mathrm{~g}$ of soil samples were prepared in $50 \mathrm{~mL}$ centrifuge tubes. Tubes were capped and tightly sealed with Parafilm ${ }^{\circledR}$ (homogenization and storage as described above). An additional set of two centrifugation tubes $(15 \mathrm{~mL})$ per water content and soil type were prepared similar to di Bonito et al. (2008) with Whatman® Grade 1 filter paper placed over the exit hole; soil was then transferred into the prepared tubes, capped, and placed inside a clean $50 \mathrm{~mL}$ centrifuge tube. The compilation of smaller centrifuge tubes equipped with filter paper placed in larger tubes are hereafter referred to as filter tubes (Figure 3). All soil samples were spun at $5000 \mathrm{rpm}$ for 15 minutes on an Eppendorf centrifuge model 5804 (Eppendorf Corp., Hamburg, DE). Initial tests showed that centrifugation times of $<30$ min were sufficient, after which no more water could be extracted at a particular speed. Relative centrifugal force was converted to soil water tensions using

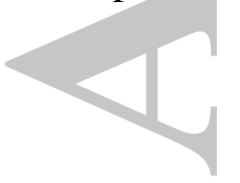

This article is protected by copyright. All rights reserved. 
transformations based on simple soil physics (Edmunds and Bath, 1976; Figueroa-Johnson et al., 2007). A calculated tension of approximately $30 \mathrm{kPa}$ was applied to all soil samples.

\subsubsection{Mechanical squeezing}

For mechanical squeezing, $400 \mathrm{~g}$ of soil was added to a Ziploc® bag with subsequent reference water addition. Bags were sealed after squeezing out excess air, and massaged for homogenization. The samples were subsequently placed in a second Ziploc® bag and equilibrated as described above. The high pressure mechanical squeezers used for this study were constructed similar to Böttcher et al. (1997) and consisted of a stainless steel chamber with a porous stainless steel filter disk at the exit port and a brass piston applying compression to the top of the sample. Soil samples were transferred from the Ziploc® bag into the squeezer chamber, a syringe was attached to the exit port, and piston placed at the top. Pressure was applied via a hydraulic jack to a maximum of $10000 \mathrm{psi}$ (68.95 MPa) and held at that pressure for 24 hours. Water was expelled from the soil through a stainless steel sintered filter at the bottom of the stainless steel squeezing cylinder directly into a syringe. Special precautions were taken to ensure that neither the soil sample, nor the expelled water came into contact with the atmosphere during this process.

\subsubsection{Direct vapor equilibration method}

Soil samples were prepared similarly to the samples for mechanical squeezing: $400 \mathrm{~g}$ of soil were added to a Ziploc ${ }^{\circledR}$ bag, with subsequent amounts of reference water. Ziploc® bags were evacuated, sealed and massaged to homogenize, placed inside a second Ziploc® bag, and stored to equilibrate prior to analysis. We followed protocols of Hendry et al. (2015) and Wassenaar et al. (2008), whereby the Ziploc $®$ bags containing the soil samples were inflated 
with dry air, sealed, and allowed to equilibrate at room temperature for additional three days prior to water vapor isotope analysis.

\subsubsection{Microwave extraction}

For microwave extraction, $25 \mathrm{~g}$ of each soil sample was prepared directly into glass scintillation vials. Vials were capped and tops wrapped with Parafilm®. After equilibration as described above, the sample material was transferred to the extraction vessel in the microwave and evenly distributed across the base of the container. The microwave extraction setup was constructed following Munksgaard et al. (2014). A domestic microwave was coupled with an IWA-45EP Analyzer (Los Gatos Research Inc., Mountain View, US). Through microwave irradiation within a sealed vessel including the soil sample, water was extracted into a dry air stream. The evolving water vapor was directed into a cooled condensation chamber, which controls the water vapor concentration and flow rate to the analyzer. Microwave power was set to $300 \mathrm{~W}$ for 15 min analogous to Munksgaard et al. (2014). For drift corrections and calibrations, in-house liquid water standards were run after every fourth sample. A piece of filter paper (Whatman ${ }^{\circledR} 541$ ) was placed inside the extraction container and $0.3 \mathrm{ml}$ of water standard was added to the filter paper. The filter paper caused water to be distributed across a large surface area as per Munksgaard et al. (2014). The same water extraction procedure was performed for the water standards as for the soil samples. $\delta^{18} \mathrm{O}$ and $\delta^{2} \mathrm{H}$ values were derived after machine specific humidity corrections were applied to each sample data-set following the protocols outlined by Schmidt et al. (2010) for the specific isotopic analyzer used for this study.

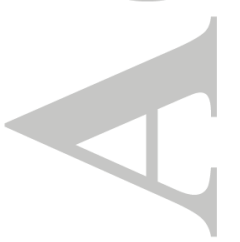

This article is protected by copyright. All rights reserved. 


\subsection{Isotope analyses}

For cross-checking the isotope results and ruling out potential analytical differences, the isotopic composition of all water samples were analyzed via both Off-Axis Integrated Cavity Output Spectroscopy (OA-ICOS) and isotope-ratio mass spectrometry (IRMS) if a sufficient amount of water could be extracted. Samples for IRMS were run on a Delta VTM Advantage mass spectrometer (Thermo Fisher Scientific, Waltham, MA, US) and an H/Device peripheral using a Cr-reduction method for ${ }^{2} \mathrm{H}$ analysis. For ${ }^{18} \mathrm{O}$ analysis, a GasBench II peripheral was utilized. In-house standards, established by runs with VSMOW2 and SLAP2, were run as samples to allow the results to properly be reported against VSMOW (see Nelson, (2000)). Results are accurate to $\pm 1 \%$ for $\delta^{2} \mathrm{H}$ and to $\pm 0.2 \%$ or $\delta^{18} \mathrm{O}$, respectively. Liquid water samples for OA-ICOS were analyzed on an IWA-45EP Analyzer (Los Gatos Research Inc., Mountain View, US). Accuracy of OA-ICOS analyses was $\pm 0.5 \%$ for $\delta^{2} \mathrm{H}$ and $\pm 0.1 \%$ for $\delta^{18} \mathrm{O}$. The IWA-45EP Analyzer was likewise used for water vapor measurements of the direct vapor equilibration method and the microwave extraction. For these measurements, results are accurate to $\pm 0.2 \%$ for $\delta^{2} \mathrm{H}$ and to $\pm 0.05 \%$ for $\delta^{18} \mathrm{O}$ for a $100 \mathrm{sec}$ reading period, respectively. All isotopic ratios are reported in per mil (\%) relative to Vienna Standard Mean Ocean Water (VSMOW) (Craig, 1961). Isotopic data of soil water extracts were checked for spectral interferences using the Spectral Contamination Identifier (LWIASCI) post-processing software (Los Gatos Research Inc.) when measured via OA-ICOS. No sample was found to be contaminated with organics such as potentially co-extracted methanol, ethanol, acids, glycols, and other species. However, these co-distillates typically occur in plant water extracts (Leen et al., 2012).

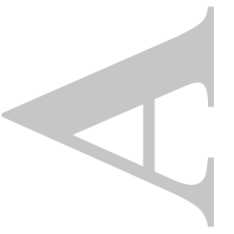

This article is protected by copyright. All rights reserved. 


\subsection{Statistical evaluation}

For statistical analyses, we used IBM SPSS Statistics (Version 22, SPSS Inc., Chicago, IL, US). For quantifying any methods differences, effects of soil type and water content, the obtained isotope data were tested for normal distribution. Subsequently, Multivariate Analyses of Variances (MANOVAs) were applied and either Dunnett-T3 or Tukey-B tests were run to determine which groups were significantly different $(\mathrm{p} \leq 0.05)$.

To evaluate the performance or proficiency of each extraction method, a target standard deviation (SD) was set to $2 \%$ for $\delta^{2} \mathrm{H}$ and $0.2 \%$ for $\delta^{18} \mathrm{O}$ for liquid water and vapor samples measured via OA-ICOS and IRMS. The target SD was selected based on similar studies (Wassenaar et al. 2012) and a combination of standard errors.

We determined Z-scores for each method using the assigned target SD. Z-scores show how far the extracted water isotopic ratios differed from the reference water used for spiking. The Z-scores were calculated for each sample and isotope according to Wassenaar et al. (2012):

$$
Z=\frac{(E-R)}{\mu}
$$

where, E was the extracted $\delta^{2} \mathrm{H}$ or $\delta^{18} \mathrm{O}$ value, respectively, $\mathrm{R}$ was the $\delta^{2} \mathrm{H}$ or $\delta^{18} \mathrm{O}$ value of the reference water, and $\mu$ was the target SD. A Z-score of $<|2|$ was considered acceptable, values from $|2-5|$ were considered questionable and $>|5|$ was considered unacceptable. In contrast to Wassenaar et al. (2012), we extended the questionable and unacceptable range of Z-scores from previously $|2-3|$ to now $|2-5|$ and the unacceptable range from $>|3|$ to now $>|5|$ due to the culminating addition of standard error associated with the following SD's: labelled 
water, in-house standards, and machine precision that all may have an additional effect on the obtained isotope results. The assessment of Z-score analysis should help to identify in which ways extraction/equilibration method results are intercomparable and trustworthy.

\section{RESULTS}

Table II summarizes descriptive statistics of extracted isotopic ratios for silty sand and clayey loam obtained via the different soil water extraction methods and measured via OA-ICOS and IRMS. The range of standard deviations among methods showed that for $\delta^{18} \mathrm{O}$, squeezing and centrifugation for both soil types were consistently the most repeatable. In general, microwave extraction and the direct vapor equilibration showed the highest standard deviations over all water contents and soil types. Cryogenic extraction consistently showed intermediate variability compared to the other techniques. For the cryogenic extraction method, in particular for the CA line, the precision of the water to water extraction - run as a quality control standard during each extraction - was greater than the soil water extraction ( $\pm 0.8 \%$ and $\pm 0.2 \%$ for $\delta^{2} \mathrm{H}$ and $\delta^{18} \mathrm{O}$, respectively). Overall, high pressure mechanical squeezing provided the most consistent value closest to the labelled water for both $\delta^{2} \mathrm{H}$ and $\delta^{18} \mathrm{O}$ over both soil types and water contents $\left(-62.4 \%\right.$ to $-56.9 \%$ for $\delta^{2} \mathrm{H}$ and $-8.89 \%$ o to $-8.21 \%$ for $\left.\delta^{18} \mathrm{O}\right)$. The most inconsistent was microwave extraction. Discrepancies may be further explained by soil chemistry, extraction technique, and methodologies.

[Table II near here]

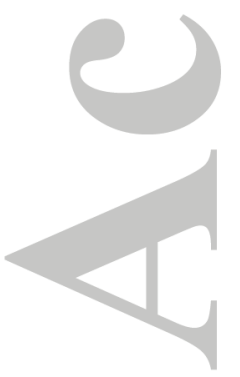

This article is protected by copyright. All rights reserved. 


\subsection{Water content and soil type effects}

\subsubsection{OA-ICOS measurements}

At $8 \%$ WC, both cryogenic extractions (CA and DE) were significantly different from all other methods for both $\delta^{2} \mathrm{H}$ and $\delta^{18} \mathrm{O}$ and for both clayey loam and silty sand material (with one exception for $\delta^{18} \mathrm{O}$ clayey loam results of microwaving) measured via OA-ICOS (Figure 1a). Both cryogenic extraction lines showed similar results and did not vary significantly between each other except for one instance for $\delta^{18} \mathrm{O}$ in the clayey loam soil at $8 \% \mathrm{WC}$. At $20 \%$ and $30 \%$ WC, both of the cryogenic lines (CA and DE) produced similar results against each other that were not statistically different. However, cryogenic extraction was inconsistently different from the other methods for 20 and $30 \% \mathrm{WC}$ and also different depending on the isotope and the lab (CA or $\mathrm{DE})$.

[Figure 1 near here]

When comparing purely mechanical methods that do not involve phase changes prior to measurement (squeezing and centrifugation), results were statistically comparable and not significantly different for any water contents tested for both soil types and for both isotopes.

The direct vapor equilibration method produced inconsistent results when comparing across water contents and soil types. At $8 \% \mathrm{WC}$, the method showed numerous statistically significant differences from all other tested methods. However, as water content increased, it shifted to only being different for clayey loam for all extraction methods and microwave extraction (for both soil types).

This article is protected by copyright. All rights reserved. 
In general, higher water contents showed less significant differences among the different extraction approaches. This was especially true for the silty sand.

\subsubsection{IRMS measurements}

For $8 \%$ WC, some extractions did not provide enough water for both IRMS and OA-ICOS analysis and other methods were only applicable using OA-ICOS such as the direct vapor equilibration or the microwave extraction method. Nevertheless, again centrifugation and squeezing showed no statistically significant differences for both isotopes and soil types at $8 \%$ WC but both differed from cryogenic extractions (except for cryogenic extractions vs. centrifugation for $\delta^{2} \mathrm{H}$ values of the clayey loam) (Figure $1 \mathrm{~b}$ ).

When comparing the $20 \%$ WC isotope values $\left(\delta^{2} \mathrm{H}\right.$ and $\left.\delta^{18} \mathrm{O}\right)$ of the different extraction methods, almost all samples showed significant differences among each other for both isotopes. Even between centrifuged and squeezed samples, statistically significant differences were observed for the clayey loam for both $\delta^{2} \mathrm{H}$ and $\delta^{18} \mathrm{O}$. However, no significant differences were observed for the sandy soil when using squeezing or centrifugation at $20 \%$ WC. In comparison to the $20 \%$ WC, the $30 \%$ WC samples again showed less significant differences among the extraction methods (Figure 1b, lower graph).

\subsection{Assessment of proficiencies by Z-score analyses}

Figure 2 shows a graphical Z-score representation of the proficiency level for each extraction method measured via OA-ICOS. A Z-score of $<|2|$ for both isotopes, indicated they fell within the pre-defined acceptable standard deviations from the consensus assigned values, while a score of $|2-5|$ indicated questionable results. For all tested extraction methods at 8\% WC, the clayey loam Z-score results plotted farthest from the origin and were 
inconsistent in spread when comparing among methods. However, squeezing and centrifugation of clay soils at $8 \%$ WC both plotted in the top right quadrant as these two methods were not significantly different and showed similar deviations from the origin. In the positive $\delta^{2} \mathrm{H}$ direction, squeezing, centrifugation, and direct vapor equilibration trended towards larger Z-scores with decreasing water content, with the clayey loam soil demonstrating the most positive Z-scores. Vapor equilibration was more or less consistent for $\delta^{2} \mathrm{H}$, but showed a positive drift in $\delta^{18} \mathrm{O}$ direction with Z-scores up to 11 . Decreasing water contents caused the greatest drift for the clayey loam. Microwave extraction exhibited a wide spread in Z-scores, especially in $\delta^{2} \mathrm{H}$ direction. Again, the $8 \% \mathrm{WC}$ of the clayey loam demonstrated unacceptable results. Generally, this method showed the worst proficiency among all tested methods since all results fell in an unacceptable range (with one exception). At lower water contents, the vapor equilibration method showed higher Z-scores for the clayey loam soil than for the silty sand, with all values falling in an unacceptable range. However, most of the silty sand results still plotted in a questionable range for the vapor equilibration technique. Cryogenic extraction showed the opposite effect, of more negative $\delta^{2} \mathrm{H}$ Z-score values with decreasing water content. On the $\delta^{18} \mathrm{O}$ axis, cryogenic extraction, centrifugation, squeezing, and vapor equilibration all trend towards a negative Z-score, with cryogenic extraction showing the most negative Z-scores. On average, the proficiency across all methods was much better for the silty sand, than for the clayey loam soil type. In most cases, excluding microwave extraction, there were acceptable Z-score results for silty sand, particularly at water contents above $8 \%$; similar trends are shown for clayey loam soil with increasing water content plotting closer to the origin, yet at an unacceptable range. Squeezing appeared to be a satisfactory method for both soil types at all water contents for silty sand and 
above $8 \% \mathrm{WC}$ for clayey loam. From a pure Z-score perspective, squeezing and centrifugation provided the best values with respect to the original reference water value for both soil types, with vapor equilibration coming in at a close third for silty sand.

[Figure 2 near here]

\subsection{Differences between IRMS- and OA-ICOS-based assays}

The dual isotope plots presented in Figure 3 (A: silty sand, B: clayey loam) illustrate the variability in dual isotope space of each method and water content with respect to the labelled reference water added to each soil type. Each plot consists of results from the OA-ICOS (main plot) and IRMS analysis (upper left corner of main plot).

For the silty sand soil type (Figure 3A), differences between methods and water contents were obvious, with microwave extraction showing strong enrichment and cryogenic extraction showing significant depletion for both isotopes. Interestingly, both of those methods were capable of completely extracting all of the soil pore water but due to their mode of operation, create vastly opposite effects on the measured isotopic ratio. Methods that were generally consistent or close to the reference water for both isotopes included squeezing and centrifugation with both extraction methods showing slight depletion with respect to $\delta^{2} \mathrm{H}$, with squeezing at $8 \% \mathrm{WC}$ performing the worst between them. Comparing results from IRMS to OA-ICOS showed very slight differences between measured isotopic values. For silty sand, differences between values (IRMS vs. OA-ICOS) over all methods tested range from $0-0.6 \%$ for $\delta^{18} \mathrm{O}$, and $0.1-1.3 \%$ for $\delta^{2} \mathrm{H}$. Generally, for the mechanical methods 
(squeezing and centrifugation), the IRMS results were slightly lower than the OA-ICOS results. The high correlation of data provided for each method between both instruments demonstrates that the less expensive, rapid option of the OA-ICOS is a viable alternative for routine, accurate isotope analyses for waters with low concentrations of organic compounds.

[Figure 3 near here]

For the clayey loam soil type (Figure 3B), differences between methods and water contents follow the same patterns as the silty sand soil type but are larger. Similarly to the silty sand, cryogenic extraction shows significant depletion for both isotopes with the most depletion occurring for $\delta^{2} \mathrm{H}$ at the lowest water content. For clayey loam, differences between values (IRMS vs. OA-ICOS) over all methods tested ranged from $0.1-1.0 \%$ for $\delta^{18} \mathrm{O}$, and $0-1.5 \%$ for $\delta^{2} \mathrm{H}$, still within a good range to utilize OA-ICOS for routine analysis for all methods at applicable water contents.

\section{DISCUSSION}

\subsection{Extraction methods and their effects on $\delta^{18} \mathrm{O}$ and $\delta^{2} H$}

Out of the five methods compared, mechanical squeezing and centrifugation showed the highest proficiency for both soil types and individual isotopes of $\delta^{2} \mathrm{H}$ and $\delta^{18} \mathrm{O}$. Interesting differences were observed between many of the methods with respect to individual isotope shifts compared to the label water. It is possible that the mechanics of each method, or the phase changes that the water molecule went through as part of the specific extraction process prior to analysis, may have affected the resulting isotopic ratio. For example, when 
comparing the two mechanically based methods of extracting water (squeezing and centrifugation), the effects on $\delta^{2} \mathrm{H}$ were opposite, with squeezing showing depletion and centrifugation showing enrichment (but with similar results for $\delta^{18} \mathrm{O}$ ). We expected both methods to provide consistent results, but differences were apparent, especially for the clayey loam soil.

The three methods that underwent significant phase changes (microwave, direct vapor equilibration, and cryogenic extraction) exhibited the largest isotopic discrepancies compared to the labeled water. Cryogenic extraction became more depleted in $\delta^{18} \mathrm{O}$ and $\delta^{2} \mathrm{H}$; microwave more enriched in $\delta^{2} \mathrm{H}$ with mixed results for $\delta^{18} \mathrm{O}$ depending on soil type; direct vapor equilibration (at least for silty sand) more accurate for both isotopes but with enrichment in $\delta^{18} \mathrm{O}$ for the clayey loam soil. Others have shown recently that cryogenic extraction can show depleted $\delta^{18} \mathrm{O}$ values for incomplete extractions (Munksgaard et al., 2014; Sprenger et al., 2015a). Notwithstanding, our study had complete extractions as measured by the water content results (not applicable to microwaving and direct vapor equilibration) but still showed depletion in $\delta^{18} \mathrm{O}$. For direct vapor equilibration, deviations from the input label was observed in relation to water content, generally affecting $\delta^{18} \mathrm{O}$ more than $\delta^{2} \mathrm{H}$ since $\delta^{2} \mathrm{H}$ is less sensitive to fractionation effects (Garvelmann et al., 2012; Sprenger et al., 2015a). Microwave extraction showed the greatest effect on $\delta^{2} \mathrm{H}$ values regardless of soil type. Many of the methods showed that $\delta^{2} \mathrm{H}$ is indeed less sensitive to fractionation effects compared to $\delta^{18} \mathrm{O}$, but the opposing effect on $\delta^{18} \mathrm{O}$ raises new questions suggesting that individual soil types play a greater role in isotope fractionation than originally thought. Isotopic fractionation effects especially affecting the $\delta^{18} \mathrm{O}$ values could be due to the formation of hydration spheres around cations (Sofer and Gat, 1972). Meißner et al. (2014) also found that the presence of 
carbonates significantly altered the $\delta^{18} \mathrm{O}$ values of added water, whereas the shift in $\delta^{2} \mathrm{H}$ values between added and extracted water was independent from the carbonate content (see section 4.3).

\subsection{Measurement error and uncertainty}

In addition to the methods comparison, precision associated with analytical and laboratory equipment must be assessed. This will compound any differences across different method types. The associated uncertainty of the labelled water, the in-house standard used to define the OA-ICOS results, and the standard error associated with the OA-ICOS measurement, the minimum standard deviation for this study was approximately 3\%o for $\delta^{2} \mathrm{H}$ and $0.6 \%$ for $\delta^{18} \mathrm{O}$. This does not take into account any errors associated with weighing soils, volumetric water additions to the sample, or any standard deviations related to each particular method.

Others have likewise examined such measurement uncertainties. Koeniger et al. (2011) performed cryogenic extraction on spiked replicates of both sand and clayey soils and found significant differences for each soil type, with clayey soils having nearly $2 \%$ more deviation than sand for $\delta^{2} \mathrm{H}$ and $0.23 \%$ more for clay of $\delta^{18} \mathrm{O}$. Wassenaar et al. (2008) reported repeatability in clay soils spiked with water of $0.7 \%$ for $\delta^{2} \mathrm{H}$ and $0.02 \%$ for $\delta^{18} \mathrm{O}$ using the direct vapor equilibration method, but generally precision decreased to $2.1 \%$ for $\delta^{2} \mathrm{H}$ and $0.4 \%$ for $\delta^{18} \mathrm{O}$ for this technique (Hendry et al., 2015). We also noted instrument precision as well as reference labelled differences used to rewet the soil. Water-to-water cryogenic extraction was performed in both labs $(\mathrm{CA}$ and $\mathrm{DE})$ to determine the precision of each system prior to application to soils. The CA lab showed precision of $\pm 0.41 \%$ or $\delta^{2} \mathrm{H}$ and $\pm 0.12 \%$ o for $\delta^{18} \mathrm{O}(\mathrm{n}=119)$, while the DE system was fully tested in regard to this by Orlowski et al. 
(2013) using different types of water. For instance, extractions with local tap water resulted in no significant differences between the untreated $\left(-56.74 \% 0 \pm 0.36\right.$ for $\delta^{2} \mathrm{H}$ and $-9.28 \% \pm \pm 0.11$ for $\left.\delta^{18} \mathrm{O}\right)$ and extracted tap water $\left(-57.49 \% \pm \pm 0.58\right.$ for $\delta^{2} \mathrm{H}$ and $-9.40 \% 0 \pm 0.12$ for $\left.\delta^{18} \mathrm{O}\right)$. Munksgaard et al. (2014) reported precision during microwave extraction of better than 2\%o for $\delta^{2} \mathrm{H}$ and $0.3 \%$ for $\delta^{18} \mathrm{O}$ for a sandy soil.

\subsection{Soil type and treatment effects on isotopic signature}

It is common practice to use oven-dried soils and rewetting to perform laboratory based experiments for methodology standardization (Koeniger et al., 2011; Oerter et al., 2014; Orlowski et al., 2013; Savin and Epstein, 1970; Sprenger et al., 2015a; VanDeVelde and Bowen, 2013; Volkmann and Weiler, 2014). This common practice is based on the premise that all water in the soil is evaporated by oven-drying and only the water added afterwards for recovery experiments will be measured. However, what is typically neglected for clay soils in particular is the interlayer and adsorbed water that may also be changed, left behind or completely removed during this process. Early on, Savin and Epstein (1970), and later VanDeVelde and Bowen (2013) have demonstrated that the removal of interlayer and adsorbed water on clay soils can occur when they were heated at 100 to $300^{\circ} \mathrm{C}$ under vacuum. Savin and Epstein (1970) also observed atmospheric vapor isotopic exchange with interlayer water (almost completely) within hours. They demonstrated that the isotopic composition of clay interlayer and adsorbed water can reflect the isotopic composition of atmospheric water vapor at the storage location; however, once the soil had been heated under vacuum and the interlayer water was removed, the water that remained showed no isotopic exchange. Recently, Sprenger et al. (2015a) questioned the common practice of spiking experiments with dry soils and suggested using field wet soils for comparison studies 
instead; however, the true isotopic signature would be unknown for field soil samples. In our study, soil samples were oven-dried using standard methods at least twice prior to any rewetting and stored in a desiccation chamber until use. We also used higher drying temperatures and longer durations $\left(72 \mathrm{~h}, 120^{\circ} \mathrm{C}\right)$ than usually applied in other studies (e.g. Koeniger et al., 2011; Meißner et al., 2014; West et al., 2006). However, drying for this study was not done under vacuum, so it can be assumed that not all of the clay interlayer and adsorbed water was removed or made non-isotopically exchangeable, which could explain some of the discrepancies throughout many of the methods tested, especially at low water contents. For the low water contents used in this study, the amount of available water fraction was small $\mid$ and exchange with interlayer and adsorbed water would be high. In hindsight, repeating this with soils dried under vacuum and higher temperatures may help identify this phenomenon. A co-extraction of organic compounds such as methanol, ethanol, acids, glycols, and others as observed by Leen et al. (2012) and West et al. (2010) leading to sample contamination can be neglected for both soil types in our study since no significant differences between OA-ICOS and IRMS results were observed, which could have indicated such organic contamination effects. Moreover, the LWIA-SCI software did not detect any contaminated samples which would have occurred when organics were co-extracted. As tested by West et al. (2011), the manufacturers' software appropriately identifies problematic samples; however, it does not resolve the underlying problem of contamination affecting laser-absorption based measurements.

Another issue affecting extracted isotope results can be the presence of organic matter (organic carbon content) in soil samples. An intercomparison water recovery experiment by Walker et al. (1994) had difficulties getting back the added reference water from dry and wet 
clays, sand, and gypseous sand. The authors assumed that decomposition of organic matter or extraction of crystallization water could have biased isotope effects. Recently, Orlowski et al. (2016) observed that $\delta^{2} \mathrm{H}$ values decreased with increasing organic carbon content when using cryogenic extraction. Thus, research is urgently needed to analyze the full extent of soil organic matter i.e. exchangeable bonded hydrogen (Meißner et al., 2014) in organic-rich soils on the extracted isotopic composition (Orlowski et al., 2016). The different existing exchangeable (labile) hydrogen fractions in environmental organic matter $(\mathrm{O}-, \mathrm{N}-$, and $\mathrm{S}-$ bonded or aromatic hydrogen) can easily interact with ambient water or water vapor (Ruppenthal et al., 2010) and thus are assumed to cause isotope effects. However, the effect of organic carbon content on isotope results obtained via extraction/equilibrium methods other than cryogenic extraction is still not known.

Further isotopic fractionation effects due to chemical reactions or high salt concentrations as observed by Oerter et al. (2014) may also explain some of the discrepancies between methods at specific water contents. Oerter et al. (2014) showed that isotope effects due to soil type are more common in soils with higher cation exchange capacity at low water contents. This can be further exacerbated by the cations present in the soil. Those soils with high ionic potential (e.g. $\mathrm{Ca}^{2+}$ and $\mathrm{Mg}^{2+}$ ) can create large amounts of structured water around the ion (hydrated radii) compared to the bulk water in the system. O'Neil and Truesdell (1991) theorized that from an oxygen isotope perspective, such cations are capable to cause fractionation between bound and bulk soil water. Moreover, soils higher in potassium ions may have a greater effect on hydrogen isotopes, while sodium soils demonstrate non-fractionating effects (Oerter et al., 2014). These cation fractionation effects for montmorillonitic soils in particular can result in depletion of up to $1.55 \%$ in dry soils and $0.49 \%$ for $\delta^{18} \mathrm{O}$ for wet soils. Others likewise 
observed that the isotopic fractionation effect due to hydration is more pronounced when only little water is added (e.g. Ingraham and Shadel, 1992; Meißner et al., 2014; Walker et al., 1994). In soils with high water contents, the volume of water affected by hydration is small in comparison to the extracted water (Sprenger et al., 2015a). This is why hydration has no measurable effect on the isotope analysis (Sprenger et al., 2015a).

In our study, chemical and salt effects can be ignored for the silty sand due to a low cation exchange capacity of $4.1 \mathrm{meq} 100 \mathrm{~g}^{-1}$, whereas the high cation exchange capacity (30.6 meq $\left.100 \mathrm{~g}^{-1}\right)$ of the clayey loam soil may have caused some of the detrimental effects seen across the methods, especially at low water contents due to ion hydration effects among the cations present.

\subsection{How to choose which method to use?}

Ultimately, the goal of each individual study will dictate which methods are suitable for the particular results, sample types, timeline, cost, and needed precision. For example, if one is interested in delineating process-affected water from a mine in a reclamation landscape, as compared to precipitation or shale pore water in the same landscape, all of these techniques would in essence, provide a clear picture. For these kinds of studies, compromises in accuracy are acceptable since isotopic variations among these types of waters are generally higher and can still be distinguished.

However, when factoring costs and time involved in analysis are important factors in a particular study, the direct vapor equilibration method is the least expensive and least time consuming choice. However, tradeoffs in accuracy are sacrificed with direct vapor equilibration, especially in low water content soils $(<5 \%$ gravimetric water content of less 
than $3 \mathrm{~g}$ of water in the sample) and consolidated shales (Hendry et al., 2015; Wassenaar et al., 2008). Sample storage time and storage containers must also be considered when using this method. Hendry et al. (2015) showed that this method is analytically reproducible using Ziploc ${ }^{\circledR}$ freezer bags for storage times less than 10 days, while storage for longer periods of time may cause fractionation of the isotopic signal due to evaporation or microbial activity. Sprenger et al. (2015a) showed storage times of up to 30 days when using laminated coffee bags with up to $90 \%$ less water loss than Ziploc bags after 30 days. To eliminate microbial activity effects, others have recommended sterilization (Hsieh et al., 1998). There is also no defined standard for headspace equilibration times across sample types with equilibration times varying from 15 h to 7 days (Garvelmann et al., 2012; Hendry et al., 2013; Mueller et al., 2014; Sprenger et al., 2015b). Our results further suggest that this method produces results that differ significantly from other methods except at higher water contents in silty sand. However, at water contents above $20 \%$ very similar results were demonstrated in the silty sand as compared to squeezing and centrifugation. This means that at higher water contents and in coarse soils the results from direct equilibration, squeezing, and centrifugation would generally be cross-comparable.

For matching plant waters to soil water sources in ecohydrological settings, much higher precisions would be required than for the previous scenario. To answer research questions about which water pool/s plants may be accessing (although recent work suggests that such water is likely at a scale poorly represented by sample sizes in each of our methods compared-(Evaristo et al., 2016)), there may only be very small differences in isotope ratios, making precision a top priority, no matter the cost. According to the results of our study, high pressure mechanical squeezing or centrifugation are the best options. Contrary to 
Kelln et al. (2001), squeezed samples in this study showed small deviation from the added reference water compared to all other methods, even for the clayey loam. Squeezing conversely, has a high capital cost upfront with a low consumable cost and is very manpower intensive and time consuming; while centrifugation has a similar capital cost, is less time consuming and large numbers of samples (8-24 samples depending on rotor size every 15 minutes) can be processed daily. If squeezing is the selected extraction method, care must be taken with respect to sample storage; normally, less than 10 samples will be processed for each 24 hour period, so it could take weeks to months to get through a large sampling program, consequently, storage stability is paramount. Also, squeezing coarser soils at low water contents is sometimes not possible. Since isotope values obtained from both squeezing and centrifugation closely match the added reference water for this study, we would recommend either of these methods if a sufficient amount of soil sample material $(>200 \mathrm{~g}$ for squeezing and $>50 \mathrm{~g}$ for centrifugation) is available so that an adequate volume of water for isotope analysis can be withdrawn from samples.

Currently, cryogenic extraction is the most common tool for extracting both plant and soil water (Orlowski et al., 2016). The attractiveness of this method is the ability to obtain measurable amounts of water from very small sample sizes $(<10 \mathrm{~g})$. However, cryogenic extraction involves high capital and operating costs (e.g. costs for system maintenance or liquid nitrogen) and is time consuming. ${ }^{1}$ Soils also present their own set of unique challenges during cryogenic extraction as pointed out in this study and others (e.g. Orlowski et al.,

\footnotetext{
${ }^{1}$ Many plant species also expel alcohols along with the extracted water and can subsequently only be analyzed on IRMS (costly and time consuming) instead of the faster, less expensive OA-ICOS (West et al., 2010). Also, thus far, none of the isotope effects associated with soils have been observed during plant water extractions (Koeniger et al., 2011; Munksgaard et al., 2014; Peters and Yakir, 2008). Therefore, plant water extractions are assumed not to be problematic in this regard.
}

This article is protected by copyright. All rights reserved. 
2016). The extreme temperature and pressure conditions during extraction are likely to mobilize both hygroscopic (Koeniger et al., 2011) and biologically bound water (Sprenger et al., 2015a). In addition, cryogenic extraction may have an effect on removal of clay interlayer water and hydrogen bonds as already discussed. Some have suggested utilizing higher temperatures for clayey loam soil types for recovering initial isotopic composition, as well as the extraction of ad- and absorbed water attached to clay minerals (Araguás-Araguás et al., 1995; Walker et al., 1994). These studies have also shown that extraction temperatures may affect isotope results. Many studies (Koeniger et al., 2011; Orlowski et al., 2013; West et al., 2006) including this one, show essentially complete extraction in terms of water recovery by weight (our recovery was $>99 \%$ ). For the two soil types tested, we observed statistically similar results on both cryogenic systems showing that when exact experimental guidelines are followed on the same set of soils, results are cross-comparable to each other (see Orlowski et al., 2016 for further discussion).

Cryogenic extraction and microwave extraction are similar in that they both use heat (approximately $60-80{ }^{\circ} \mathrm{C}$ for microwave and $>90{ }^{\circ} \mathrm{C}$ for cryogenic) and vacuum $(970 \mathrm{hPa}$ over 10 min (Munksgaard et al., 2014) for microwave and $0.1 \mathrm{~Pa}$ for cryogenic). Since microwave extraction for water extraction is new, little is known about the effects soil properties play on the isotope results. Other issues such as phase change, temperature, and pressure effects associated with this method are also still poorly understood. Although the method shows promise, much more needs to be done with respect to delineating all the factors that may influence the extracted isotopic composition. Further work is needed to precisely determine which set of parameters (e.g. time, irradiation) work best for specific soil types and water contents. The ability to rapidly extract water in vapor form coupled directly 
to an OA-ICOS is an attractive future option and could potentially be one of the quickest and least expensive methods of analysis once the methodology has been proven.

\section{CONCLUSIONS}

We have examined five different soil water extraction methods used for the analysis of the stable isotopes of water on two physicochemically different soil types (silty sand and clayey loam) at three water contents $(8 \%, 20 \%$, and 30\%). Recent literature has called for intercomparison between the methods (McDonnell, 2014; Orlowski et al., 2016; Sprenger et al., 2015a) used to study water movement through soil profiles at hillslope and watershed scales, mine reclamation landforms and benchtop studies of soil pore water and its interaction with minerals. This study is the first to encompass five commonly used extraction methods within a very explicit set of parameters e.g. using the same standard soil material and water contents throughout all of our intercomparison experiments.

We compared $\delta^{2} \mathrm{H}$ and $\delta^{18} \mathrm{O}$ analyses on both an OA-ICOS and IRMS, with insignificant differences in results recorded between the two, showing that organic contamination (via e.g. methanol, ethanol, acids, glycols, and similar species) was non-detectable. For studies demanding extremely precise results or with potential organic contamination, water extraction techniques and machine selection are critical. The now-standard cryogenic extraction technique was outperformed by both squeezing and centrifugation with respect to labelled water isotopic recovery ratio. For studies requiring less precision, the direct vapor equilibration method is suitable, with precision being greater for sandy soil and nearly comparable to centrifugation. Microwave extraction protocols are still developing and we would caution (at this time) such use as a standard approach for soil water extraction. Overall, soil type had a direct effect on many of the methods associated with a phase change 
(cryogenic extraction, microwave, direct vapor equilibration), while those methods involving purely mechanical forces tended to produce similar results, comparable to each other with respect to soil type.

Lastly, although this study encompasses many techniques, questions remain, particularly for extractions from soils with low water contents. Future research should focus on clay mineralogy, organic matter, and water content effects as well as the effect of drying and rewetting on interlayer or adsorbed water. Alternative approaches should also be explored to assess whether or not the drying and rewetting process affects the isotopic composition as compared to a bulk soil collection in-situ with subsequent methods analyses.

\section{ACKNOWLEDGEMENTS}

We thank Kim Janzen, Cody Millar, and Anna Winkler for their lab-support. This research was supported by an NSERC Discovery Grant to J. J. McDonnell. The U.S. Forest Service and the U.S. Department of Energy's Office of Energy Efficiency and Renewable Energy, Bioenergy Technologies Office are thanked for their support.

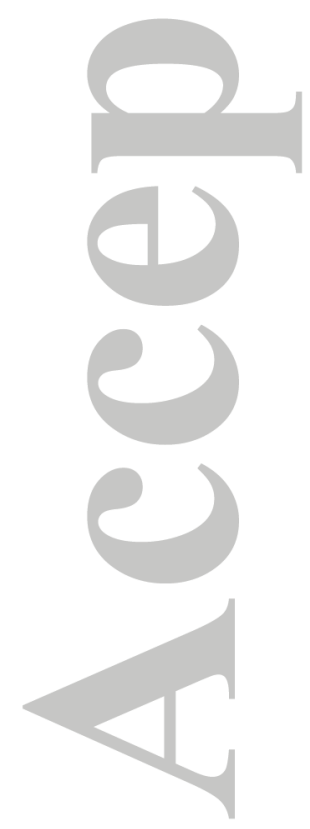

This article is protected by copyright. All rights reserved. 


\section{REFERENCES}

Araguás-Araguás, L., Rozanski, K., Gonfiantini, R. and Louvat, D.: Isotope effects accompanying vacuum extraction of soil water for stable isotope analyses, J. Hydrol., 168(14), 159-171, doi:10.1016/0022-1694(94)02636-P, 1995.

Barrow, N. J. and Whelan, B. R.: A study of a method for displacing soil solution by centrifuging with an immiscible liquid, J. Environ. Qual., 9(2), 315-319, doi:10.2134/jeq1980.00472425000900020031x, 1980.

Batley, G. and Giles, M.: Solvent displacement of sediment interstitial waters before tracemetal analysis, Water Res., 13(9), 879-886, doi:10.1016/0043-1354(79)90223-9, 1979.

di Bonito, M., Breward, N., Crout, N., Smith, B. and Young, S.: Overview of Selected Soil Pore Water Extraction Methods for the Determination of Potentially Toxic Elements in Contaminated Soils: Operational and Technical Aspects, in Environmental Geochemistry: site characterization, data analysis and case histories, edited by B. de Vivo, H. E. Belkin, and A. Lima, pp. 213-249, Elsevier, London, UK., 2008.

Böttcher, G., Brumsack, H.-J., Heinrichs, H. and Pohlmann, M.: A new high-pressure squeezing technique for pore fluid extraction from terrestrial soils, Water. Air. Soil Pollut., 94(3-4), 289-296, doi:10.1007/BF02406064, 1997.

Craig, H.: Standard for reporting concentrations of deuterium and oxygen-18 in natural waters, Science, 133(3467), 1833, 1961.

Dalton, F. N.: Plant root water extraction studies using stable isotopes, Plant Soil, 111(2), $217-221,1988$.

Dawson, T. E. and Ehleringer, J. R.: Isotopic enrichment of water in the "woody" tissues of plants: Implications for plant water source, water uptake, and other studies which use the stable isotopic composition of cellulose, Geochim. Cosmochim. Acta, 57(14), 3487-3492, doi:10.1016/0016-7037(93)90554-A, 1993.

Dubbert, M., Piayda, A., Cuntz, M., Correia, A. C., Costa e Silva, F., Pereira, J. S. and Werner, C.: Stable oxygen isotope and flux partitioning demonstrates understory of an oak savanna contributes up to half of ecosystem carbon and water exchange, Front. Plant Sci., 5, doi:10.3389/fpls.2014.00530, 2014.

Edmunds, W. M. and Bath, A. H.: Centrifuge extraction and chemical analysis of interstitial waters, Environ. Sci. Technol., 10(5), 467-472, 1976.

Ehleringer, J. R., Roden, J. and Dawson, T. E.: Assessing Ecosystem-Level Water Relations Through Stable Isotope Ratio Analyses, in Methods in Ecosystem Science, edited by O. E. Sala, R. B. Jackson, H. A. Mooney, and R. W. Howarth, pp. 181-198, Springer, New York, NY, USA., 2000. 
Evaristo, J., McDonnell, J. J., Scholl, M. A., Bruijnzeel, L. A. and Chun, K. P.: Insights into plant water uptake from xylem-water isotope measurements in two tropical catchments with contrasting moisture conditions, Hydrol. Process., in press, doi:10.1002/hyp.10841, 2016.

Figueroa-Johnson, M. A., Tindall, J. A. and Friedel, M.: A Comparison of ${ }^{18} \mathrm{O} \delta$ Composition of Water Extracted from Suction Lysimeters, Centrifugation, and Azeotropic Distillation, Water. Air. Soil Pollut., 184(1-4), 63-75, doi:10.1007/s11270-007-9399-8, 2007.

Gaj, M., Beyer, M., Koeniger, P., Wanke, H., Hamutoko, J. and Himmelsbach, T.: In-situ unsaturated zone stable water isotope $\left({ }^{2} \mathrm{H}\right.$ and $\left.{ }^{18} \mathrm{O}\right)$ measurements in semi-arid environments: a soil water balance, Hydrol. Earth Syst. Sci., 20, 715-731, doi:10.5194/hess-20-715-2016, 2016.

Garvelmann, J., Kuells, C. and Weiler, M.: A porewater-based stable isotope approach for the investigation of subsurface hydrological processes, Hydrol. Earth Syst. Sci., 16(2), 631-640, doi:10.5194/hess-16-631-2012, 2012.

Goebel, T. S. and Lascano, R. J.: System for high throughput water extraction from soil material for stable isotope analysis of water, J. Anal. Sci. Methods Instrum., 02(04), 203-207, doi:10.4236/jasmi.2012.24031, 2012.

Hendry, M. J., Barbour, S. L., Novakowski, K. and Wassenaar, L. I.: Paleohydrogeology of the Cretaceous sediments of the Williston Basin using stable isotopes of water, Water Resour. Res., 49(8), 4580-4592, doi:10.1002/wrcr.20321, 2013.

Hendry, M. J., Schmeling, E., Wassenaar, L. I., Barbour, S. L. and Pratt, D.: Determining the stable isotope composition of pore water from saturated and unsaturated zone core: improvements to the direct vapour equilibration laser spectrometry method, Hydrol. Earth Syst. Sci., 19(11), 4427-4440, doi:10.5194/hess-19-4427-2015, 2015.

Hsieh, J. C. C., Savin, S. M., Kelly, E. F. and Chadwick, O. A.: Measurement of soil-water $\delta^{18} \mathrm{O}$ values by direct equilibration with $\mathrm{CO}_{2}$, Geoderma, 82(1-3), 255-268, doi:10.1016/S0016-7061(97)00104-3, 1998.

Ignatev, A., Velivetckaia, T., Sugimoto, A. and Ueta, A.: A soil water distillation technique using He-purging for stable isotope analysis, J. Hydrol., 498, 265-273, doi:10.1016/j.jhydrol.2013.06.032, 2013.

Ingraham, N. L. and Shadel, C.: A comparison of the toluene distillation and vacuum/heat methods for extracting soil water for stable isotopic analysis, J. Hydrol., 140(1-4), 371-387, doi:10.1016/0022-1694(92)90249-U, 1992.

Isaac, M. E. and Anglaaere, L. C. N.: An in situ approach to detect tree root ecology: linking ground-penetrating radar imaging to isotope-derived water acquisition zones, Ecol. Evol., 3(5), 1330-1339, doi:10.1002/ece3.543, 2013.

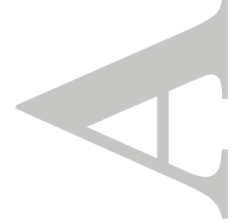

This article is protected by copyright. All rights reserved. 
Jusserand, C.: Extraction De L'Eau Interstitielle Des Sediments Et Des Sols: Comparaison Des Valeurs De L'Oxygene 18 Par Differentes Methodes Premiers Resultats, Catena, 7(1), 87-96, doi:10.1016/S0341-8162(80)80006-3, 1980.

Kelln, C. J., Wassenaar, L. I. and Hendry, M. J.: Stable Isotopes $\left(\delta^{18} \mathrm{O}, \delta^{2} \mathrm{H}\right)$ of Pore Waters in Clay-Rich Aquitards: A Comparison and Evaluation of Measurement Techniques, Ground Water Monit. Remediat., 21(2), 108-116, doi:10.1111/j.1745-6592.2001.tb00306.x, 2001.

Kendall, C. and Coplen, T. B.: Multi-sample conversion of water to hydrogen by zinc for stable isotope determination, Anal. Chem., 57(7), 1437-1440, doi:10.1021/ac00284a058, 1985 .

Koehler, G., Wassenaar, L. I. and Hendry, M. J.: An automated technique for measuring $\delta \mathrm{D}$ and $\delta^{18} \mathrm{O}$ values of porewater by direct $\mathrm{CO}_{2}$ and $\mathrm{H}_{2}$ equilibration, Anal. Chem., 72(22), 56595664, doi:10.1021/ac000498n, 2000.

Koeniger, P., Marshall, J. D., Link, T. and Mulch, A.: An inexpensive, fast, and reliable method for vacuum extraction of soil and plant water for stable isotope analyses by mass spectrometry, Rapid Commun. Mass Spectrom., 25(20), 3041-3048, doi:10.1002/rcm.5198, 2011.

Landon, M. ., Delin, G. ., Komor, S. . and Regan, C. .: Comparison of the stable-isotopic composition of soil water collected from suction lysimeters, wick samplers, and cores in a sandy unsaturated zone, J. Hydrol., 224(1-2), 45-54, doi:10.1016/S0022-1694(99)00120-1, 1999.

Landon, M. K., Delin, G. N., Komor, S. C. and Regan, C. P.: Relation of Pathways and Transit Times of Recharge Water to Nitrate Concentrations Using Stable Isotopes., Ground Water, 38(3), 381-395, doi:10.1111/j.1745-6584.2000.tb00224.x, 2000.

Leen, J. B., Berman, E. S. F., Liebson, L. and Gupta, M.: Spectral contaminant identifier for off-axis integrated cavity output spectroscopy measurements of liquid water isotopes, Rev. Sci. Instrum., 83(4), doi:10.1063/1.4704843, 2012.

Liu, Y., Xu, Z., Duffy, R., Chen, W., An, S. and Liu, S.: Analyzing relationships among water uptake patterns, rootlet biomass distribution and soil water content profile in a subalpine shrubland using water isotopes, Eur. J. Soil Biol., doi:10.1016/j.ejsobi.2011.07.012, 2011.

LUFA Speyer: German State Research Institute for Agriculture, Speyer, DE, http://www.lufa-speyer.de/index.php/dienstleistungen/standardboeden/8-

dienstleistungen/artikel/57-standard-soils (Accessed 15 April 2015), 2015.

McConville, C., Kalin, R. M. and Flood, D.: Direct equilibration of soil water for $\delta^{18} \mathrm{O}$ analysis and its application to tracer studies, Rapid Commun. Mass Spectrom., 13(13), 13391345, doi:10.1002/(SICI)1097-0231(19990715)13:13<1339::AID-RCM559>3.0.CO;2-N, 1999.

This article is protected by copyright. All rights reserved. 
McDonnell, J. J.: The two water worlds hypothesis: ecohydrological separation of water between streams and trees?, Wiley Interdiscip. Rev. Water, 1(4), 323-329, doi:10.1002/wat2.1027, 2014.

Meißner, M., Köhler, M., Schwendenmann, L. and Hölscher, D.: Partitioning of soil water among canopy trees during a soil desiccation period in a temperate mixed forest, Biogeosciences, 9(8), 3465-3474, doi:10.5194/bg-9-3465-2012, 2012.

Meißner, M., Köhler, M., Schwendenmann, L., Hölscher, D. and Dyckmans, J.: Soil water uptake by trees using water stable isotopes $\left(\delta^{2} \mathrm{H}\right.$ and $\left.\delta^{18} \mathrm{O}\right)-\mathrm{a}$ method test regarding soil moisture, texture and carbonate, Plant Soil, 376(1-2), 327-335, doi:10.1007/s11104-0131970-z, 2014.

Mubarak, A. and Olsen, R.: Immiscible displacement of soil solution by centrifugation, Soil Sci. Soc. Am. J., 40(2), 329-331, 1976.

Mueller, M. H., Alaoui, A., Kuells, C., Leistert, H., Meusburger, K., Stumpp, C., Weiler, M. and Alewell, C.: Tracking water pathways in steep hillslopes by $\delta^{18} \mathrm{O}$ depth profiles of soil water, J. Hydrol., 519, Part A, 340-352, doi:10.1016/j.jhydrol.2014.07.031, 2014.

Munksgaard, N. C., Cheesman, A. W., Wurster, C. M., Cernusak, L. A. and Bird, M. I.: Microwave extraction-isotope ratio infrared spectroscopy (ME-IRIS): a novel technique for rapid extraction and in-line analysis of $\delta^{18} \mathrm{O}$ and $\delta^{2} \mathrm{H}$ values of water in plants, soils and insects, Rapid Commun. Mass Spectrom., 28(20), 2151-2161, doi:10.1002/rcm.7005, 2014.

Nelson, S. T.: A simple, practical methodology for routine VSMOW/SLAP normalization of water samples analyzed by continuous flow methods, Rapid Commun. Mass Spectrom., 14(12), 1044-1046, doi:10.1002/1097-0231(20000630)14:12<1044::AID-

RCM987>3.0.CO;2-3, 2000.

O'Driscoll, M. A., DeWalle, D. R., McGuire, K. J. and Gburek, W. J.: Seasonal ${ }^{18} \mathrm{O}$ variations and groundwater recharge for three landscape types in central Pennsylvania, USA, J. Hydrol., 303(1-4), 108-124, doi:10.1016/j.jhydrol.2004.08.020, 2005.

Oerter, E., Finstad, K., Schaefer, J., Goldsmith, G. R., Dawson, T. and Amundson, R.: Oxygen isotope fractionation effects in soil water via interaction with cations $(\mathrm{Mg}, \mathrm{Ca}, \mathrm{K}$, $\mathrm{Na}$ adsorbed to phyllosilicate clay minerals, J. Hydrol., 515, 1-9, doi:10.1016/j.jhydrol.2014.04.029, 2014.

O'Neil, J. R. and Truesdell, A. H.: Oxygen isotope fractionation studies of solute-water interactions, in Stable Isotope Geochemistry: A Tribute to Samuel Epstein, vol. 3, edited by H. Taylor Jr., J. R. O’Neil, and I. R. Kaplan, pp. 17-25, Geochem. Soc., 1991.

Orlowski, N., Frede, H.-G., Brüggemann, N. and Breuer, L.: Validation and application of a cryogenic vacuum extraction system for soil and plant water extraction for isotope analysis, J. Sens. Sens. Syst., 2(2), 179-193, doi:10.5194/jsss-2-179-2013, 2013.

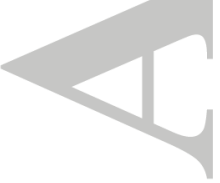

This article is protected by copyright. All rights reserved. 
Orlowski, N., Kraft, P. and Breuer, L.: Exploring water cycle dynamics through sampling multitude stable water isotope pools in a small developed landscape of Germany, Hydrol. Earth Syst. Sci. Discuss., 12(2), 1809-1853, doi:10.5194/hessd-12-1809-2015, 2015.

Orlowski, N., Breuer, L. and McDonnell, J. J.: Critical issues with cryogenic extraction of soil water for stable isotope analysis, Ecohydrol., 9(1), 1-5, doi:10.1002/eco.1722, 2016.

Peters, L. I. and Yakir, D.: A direct and rapid leaf water extraction method for isotopic analysis, Rapid Commun. Mass Spectrom., 22(18), 2929-2936, doi:10.1002/rcm.3692, 2008.

Picarro: IM-CRDS System for Isotopic Water Analysis, http://www.picarro.com/isotope_analyzers/im_crds (Accessed 17 April 2015), 2015.

Revesz, K. and Woods, P. H.: A method to extract soil water for stable isotope analysis, J. Hydrol., 115(1-4), 397-406, doi:10.1016/0022-1694(90)90217-L, 1990.

Rothfuss, Y., Biron, P., Braud, I., Canale, L., Durand, J.-L., Gaudet, J.-P., Richard, P., Vauclin, M. and Bariac, T.: Partitioning evapotranspiration fluxes into soil evaporation and plant transpiration using water stable isotopes under controlled conditions, Hydrol. Process., 24(22), 3177-3194, doi:10.1002/hyp.7743, 2010.

Rothfuss, Y., Vereecken, H. and Brüggemann, N.: Monitoring water stable isotopic composition in soils using gas-permeable tubing and infrared laser absorption spectroscopy, Water Resour. Res., 49, 1-9, doi:10.1002/wrcr.20311, 2013.

Rothfuss, Y., Merz, S., Vanderborght, J., Hermes, N., Weuthen, A., Pohlmeier, A., Vereecken, H. and Brüggemann, N.: Long-term and high-frequency non-destructive monitoring of water stable isotope profiles in an evaporating soil column, Hydrol. Earth Syst. Sci., 19(10), 4067-4080, doi:10.5194/hess-19-4067-2015, 2015.

Ruppenthal, M., Oelmann, Y. and Wilcke, W.: Isotope ratios of nonexchangeable hydrogen in soils from different climate zones, Geoderma, 155(3-4), 231-241, doi:10.1016/j.geoderma.2009.12.005, 2010.

Savin, S. M. and Epstein, S.: The oxygen and hydrogen isotope geochemistry of clay minerals, Geochim. Cosmochim. Acta, 34(1), 25-42, doi:10.1016/0016-7037(70)90149-3, 1970.

Schmidt, M., Maseyk, K., Lett, C., Biron, P., Richard, P., Bariac, T. and Seibt, U.: Concentration effects on laser-based $\delta^{18} \mathrm{O}$ and $\delta^{2} \mathrm{H}$ measurements and implications for the calibration of vapour measurements with liquid standards, Rapid Commun. Mass Spectrom., 24(24), 3553-3561, doi:10.1002/rcm.4813, 2010.

Scrimgeour, C. M.: Measurement of plant and soil water isotope composition by direct equilibration methods, J. Hydrol., 172(1-4), 261-274, doi:10.1016/0022-1694(95)02716-3, 1995. 
Sofer, Z. and Gat, J. R.: Activities and concentrations of oxygen-18 in concentrated aqueous salt solutions: Analytical and geophysical implications, Earth Planet. Sci. Lett., 15(3), 232238, doi:10.1016/0012-821X(72)90168-9, 1972.

Sprenger, M., Herbstritt, B. and Weiler, M.: Established methods and new opportunities for pore water stable isotope analysis, Hydrol. Process., doi:10.1002/hyp.10643, 2015a.

Sprenger, M., Volkmann, T. H. M., Blume, T. and Weiler, M.: Estimating flow and transport parameters in the unsaturated zone with pore water stable isotopes, Hydrol. Earth Syst. Sci., 19(6), 2617-2635, doi:10.5194/hess-19-2617-2015, 2015 b.

Stumpp, C., Maloszewski, P., Stichler, W. and Fank, J.: Environmental isotope $\left(\delta^{18} \mathrm{O}\right)$ and hydrological data to assess water flow in unsaturated soils planted with different crops: Case study lysimeter station "Wagna" (Austria), J. Hydrol., 369(1-2), 198-208, doi:10.1016/j.jhydrol.2009.02.047, 2009.

Thomas, E. M., Lin, H., Duffy, C. J., Sullivan, P. L., Holmes, G. H., Brantley, S. L. and Jin, L.: Spatiotemporal Patterns of Water Stable Isotope Compositions at the Shale Hills Critical Zone Observatory: Linkages to Subsurface Hydrologic Processes, Vadose Zone J., 12(4), 0, doi:10.2136/vzj2013.01.0029, 2013.

Thorburn, P. J., Walker, G. R. and Brunel, J. -P: Extraction of water from Eucalyptus trees for analysis of deuterium and oxygen-18: laboratory and field techniques, Plant Cell Environ., 16(3), 269-277, doi:10.1111/j.1365-3040.1993.tb00869.x, 1993.

Timbe, E., Windhorst, D., Crespo, P., Frede, H.-G., Feyen, J. and Breuer, L.: Understanding uncertainties when inferring mean transit times of water trough tracer-based lumpedparameter models in Andean tropical montane cloud forest catchments, Hydrol. Earth Syst. Sci., 18(4), 1503-1523, doi:10.5194/hess-18-1503-2014, 2014.

VanDeVelde, J. H. and Bowen, G. J.: Effects of chemical pretreatments on the hydrogen isotope composition of 2:1 clay minerals, Rapid Commun. Mass Spectrom., 27(10), 11431148, doi:10.1002/rcm.6554, 2013.

Vogel, T., Sanda, M., Dusek, J., Dohnal, M. and Votrubova, J.: Using Oxygen-18 to Study the Role of Preferential Flow in the Formation of Hillslope Runoff, Vadose Zone J., 9(2), 252, doi:10.2136/vzj2009.0066, 2010.

Volkmann, T. H. M. and Weiler, M.: Continual in situ monitoring of pore water stable isotopes in the subsurface, Hydrol. Earth Syst. Sci., 18(5), 1819-1833, doi:10.5194/hess-181819-2014, 2014.

Walker, G. R., Woods, P. H. and Allison, G. B.: Interlaboratory comparison of methods to determine the stable isotope composition of soil water, Chem. Geol., 111(1-4), 297-306, doi:10.1016/0009-2541(94)90096-5, 1994.

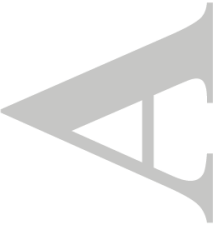

This article is protected by copyright. All rights reserved. 
Wang, P., Song, X., Han, D., Zhang, Y. and Zhang, B.: Determination of evaporation, transpiration and deep percolation of summer corn and winter wheat after irrigation, Agric. Water Manag., 105, 32-37, doi:10.1016/j.agwat.2011.12.024, 2012.

Wassenaar, L. I., Hendry, M. J., Chostner, V. L. and Lis, G. P.: High resolution pore water $\delta^{2} \mathrm{H}$ and $\delta^{18} \mathrm{O}$ measurements by $\mathrm{H}_{2} \mathrm{O}$ (liquid)- $\mathrm{H}_{2} \mathrm{O}$ (vapor) equilibration laser spectroscopy, Environ. Sci. Technol., 42(24), 9262-9267, doi:10.1021/es802065s, 2008.

Wassenaar, L. I., Ahmad, M., Aggarwal, P., van Duren, M., Pöltenstein, L., Araguas, L. and Kurttas, T.: Worldwide proficiency test for routine analysis of $\delta^{2} \mathrm{H}$ and $\delta^{18} \mathrm{O}$ in water by isotope-ratio mass spectrometry and laser absorption spectroscopy, Rapid Commun. Mass Spectrom., 26(15), 1641-1648, doi:10.1002/rcm.6270, 2012.

Weihermüller, L., Kasteel, R., Vanderborght, J., Pütz, T. and Vereecken, H.: Soil Water Extraction with a Suction Cup, Vadose Zone J., 4(4), 899, doi:10.2136/vzj2004.0156, 2005.

Wenner, D. B., Ketcham, P. D. and Dowd, J. F.: Stable isotopic composition of waters in a small Piedmont watershed, in Stable isotope geochemistry: A tribute to Samuel Epstein, edited by H. Taylor, J. O’Neill, and I. Kaplan, pp. 195-203, The Geochemical Society, , Spec. Publ. No.3, St. Louis, MO., 1991.

Wershaw, R. L., Friedman, I., Heller, S. J. and Frank, P. A.: Hydrogen isotopic fractionation of water passing through trees, in Advances in Organic Geochemistry: Proceedings of the Third International Congress, edited by F. Hobson and M. Speers, pp. 55-67, Pergamon Press Ltd., Elsevier, New York, USA., 1966.

West, A. G., Patrickson, S. J. and Ehleringer, J. R.: Water extraction times for plant and soil materials used in stable isotope analysis, Rapid Commun. Mass Spectrom., 20(8), 13171321, doi:10.1002/rcm.2456, 2006.

West, A. G., Goldsmith, G. R., Brooks, P. D. and Dawson, T. E.: Discrepancies between isotope ratio infrared spectroscopy and isotope ratio mass spectrometry for the stable isotope analysis of plant and soil waters, Rapid Commun. Mass Spectrom., 24(14), 1948-1954, doi:10.1002/rcm.4597, 2010.

West, A. G., Goldsmith, G. R., Matimati, I. and Dawson, T. E.: Spectral analysis software improves confidence in plant and soil water stable isotope analyses performed by isotope ratio infrared spectroscopy (IRIS), Rapid Commun. Mass Spectrom., 25(16), 2268-2274, doi:10.1002/rcm.5126, 2011.

White, J. W. C., Cook, E. R., Lawrence, J. R. and Wallace S., B.: The D/H ratios of sap in trees: Implications for water sources and tree ring D/H ratios, Geochim. Cosmochim. Acta, 49(1), 237-246, doi:10.1016/0016-7037(85)90207-8, 1985.

Williams, D. G. and Ehleringer, J. R.: Intra- and interspecific variation for summer precipitation use in pinyon-juniper woodlands, Ecol. Monogr., 70(4), 517-537, doi:10.2307/2657185, 2000. 
Windhorst, D., Kraft, P., Timbe, E., Frede, H.-G. and Breuer, L.: Stable water isotope tracing through hydrological models for disentangling runoff generation processes at the hillslope scale, Hydrol. Earth Syst. Sci., 18(10), 4113-4127, doi:10.5194/hess-18-4113-2014, 2014.

Zhu, Q.-Z., Sun, Q., Su, Z.-G., Xie, M.-M., Song, J.-Y., Shan, Y.-B., Wang, N. and Chu, G.Q.: A Soil Water Extraction Method with Accelerated Solvent Extraction Technique for Stable Isotope Analysis, Chin. J. Anal. Chem., 42(9), 1270-1275, doi:10.1016/S18722040(14)60766-0, 2014.
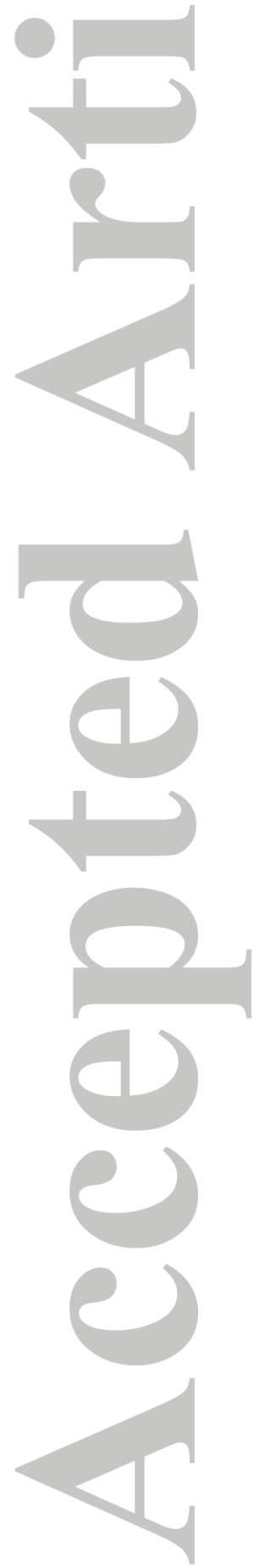

This article is protected by copyright. All rights reserved. 
Table I: Soil characteristics of LUFA 2.4 (clayey loam) and LUFA 2.1 (silty sand) (means $\pm \mathrm{SD}$ ).

\begin{tabular}{lll}
\hline Parameter & Clayey loam & Silty sand \\
\hline \hline pH-value & $7.2 \pm 0.2$ & $5.0 \pm 0.3$ \\
Water holding capacity $\left[\mathrm{g} 100 \mathrm{~g}^{-1}\right]$ & $43.4 \pm 0.8$ & $32.1 \pm 1.4$ \\
Organic carbon [\%] & $1.98 \pm 0.18$ & $0.67 \pm 0.1$ \\
Cation exchange capacity [meq $\left.100 \mathrm{~g}^{-1}\right]$ & $30.6 \pm 5.1$ & $4.1 \pm 0.6$ \\
Particle size [mm] distribution according to German DIN $[\%]$ \\
$<0.002$ & $26.0 \pm 1.5$ & $2.6 \pm 0.6$ \\
$0.002-0.006$ & $8.1 \pm 1.0$ & $1.5 \pm 0.6$ \\
$0.006-0.02$ & $15.0 \pm 1.2$ & $3.7 \pm 0.1$ \\
$0.02-0.063$ & $23.3 \pm 0.7$ & $7.5 \pm 0.6$ \\
$0.063-0.2$ & $18.9 \pm 0.3$ & $27.5 \pm 0.7$ \\
$0.2-0.63$ & $7.0 \pm 2.2$ & $54.8 \pm 1.3$ \\
$0.63-2$ & $1.7 \pm 0.2$ & $2.4 \pm 0.4$ \\
\hline
\end{tabular}

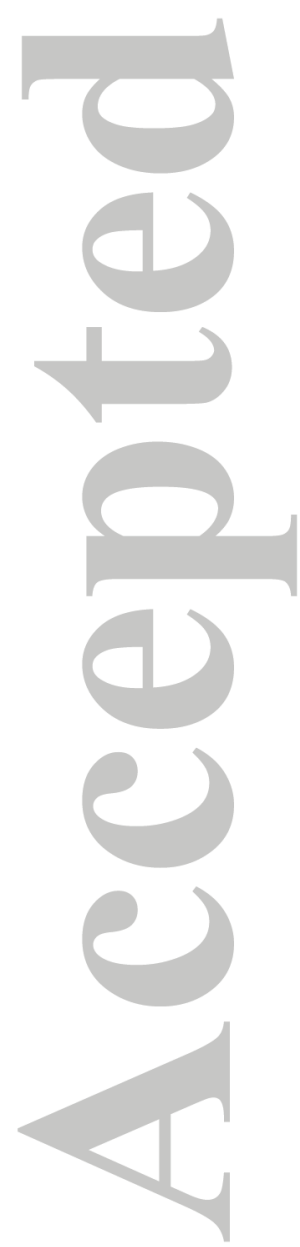

This article is protected by copyright. All rights reserved. 
Table II: Means and standard deviations (SD) of extracted $\delta^{2} \mathrm{H}$ and $\delta^{18} \mathrm{O}$ values from silty sand and clayey loam measured via OA-ICOS and IRMS for three different water contents. CA refers to cryogenic extractions performed at the system in Canada and DE in Germany, respectively.

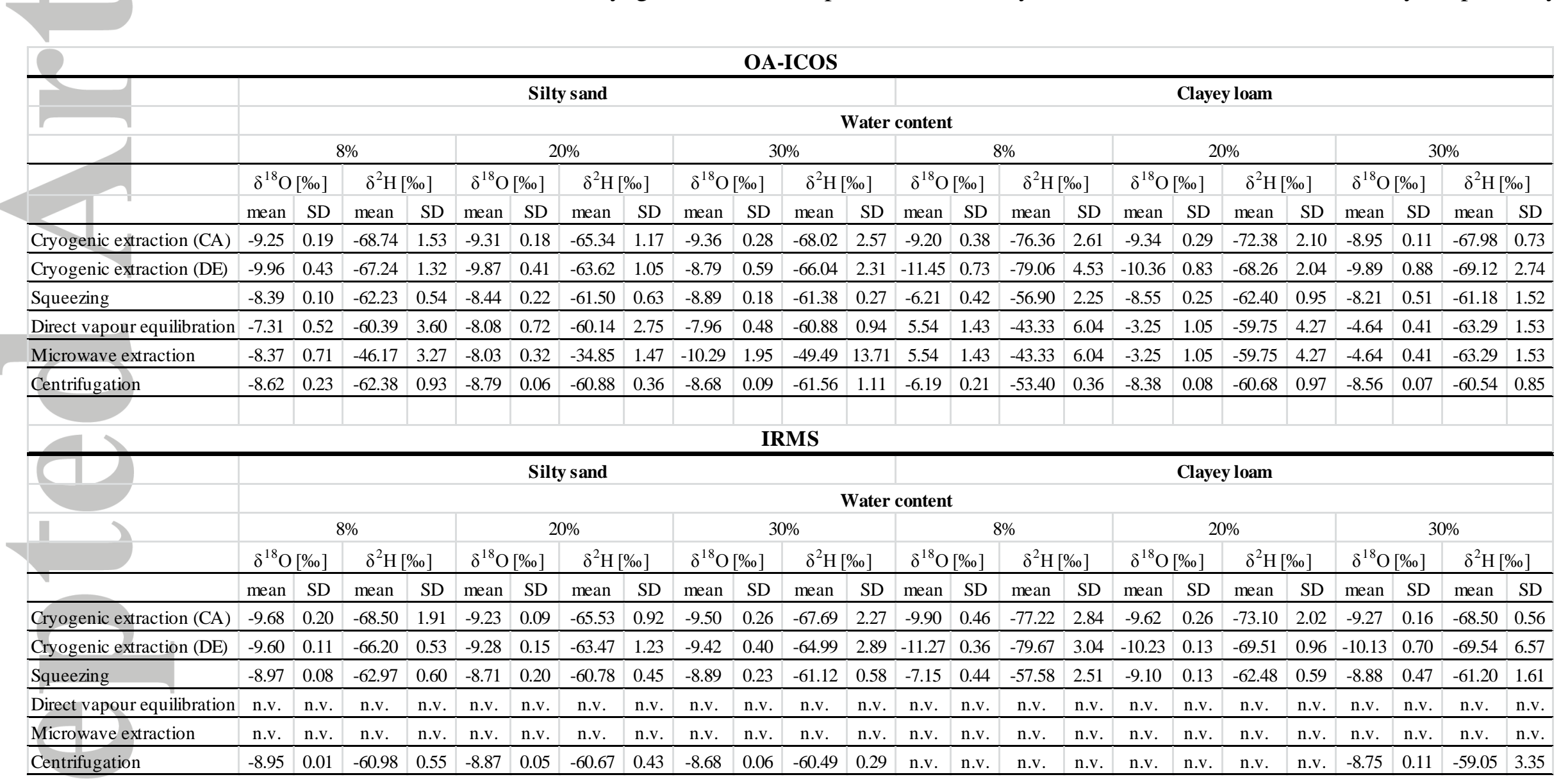

This article is protected by copyright. All rights reserved. 
(a) OA-ICOS
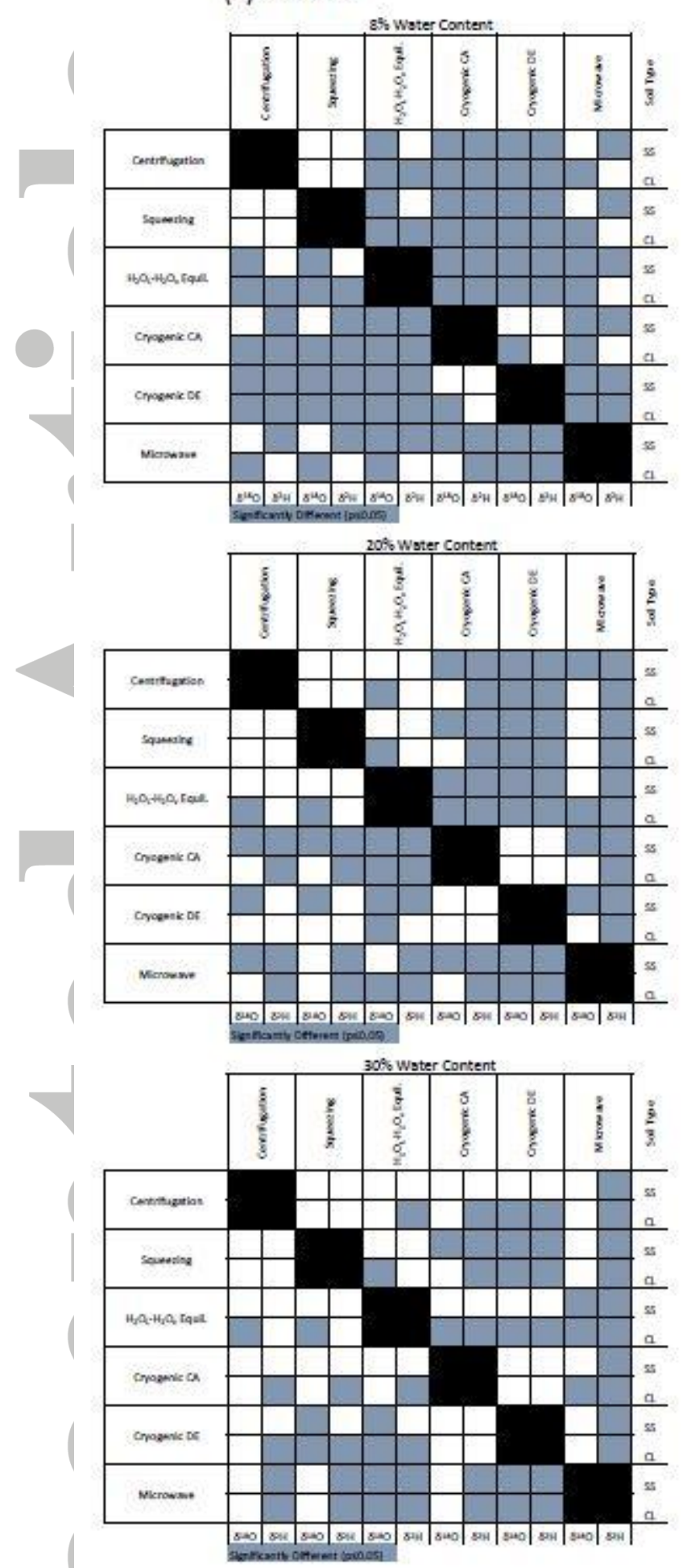

(b) IRMS
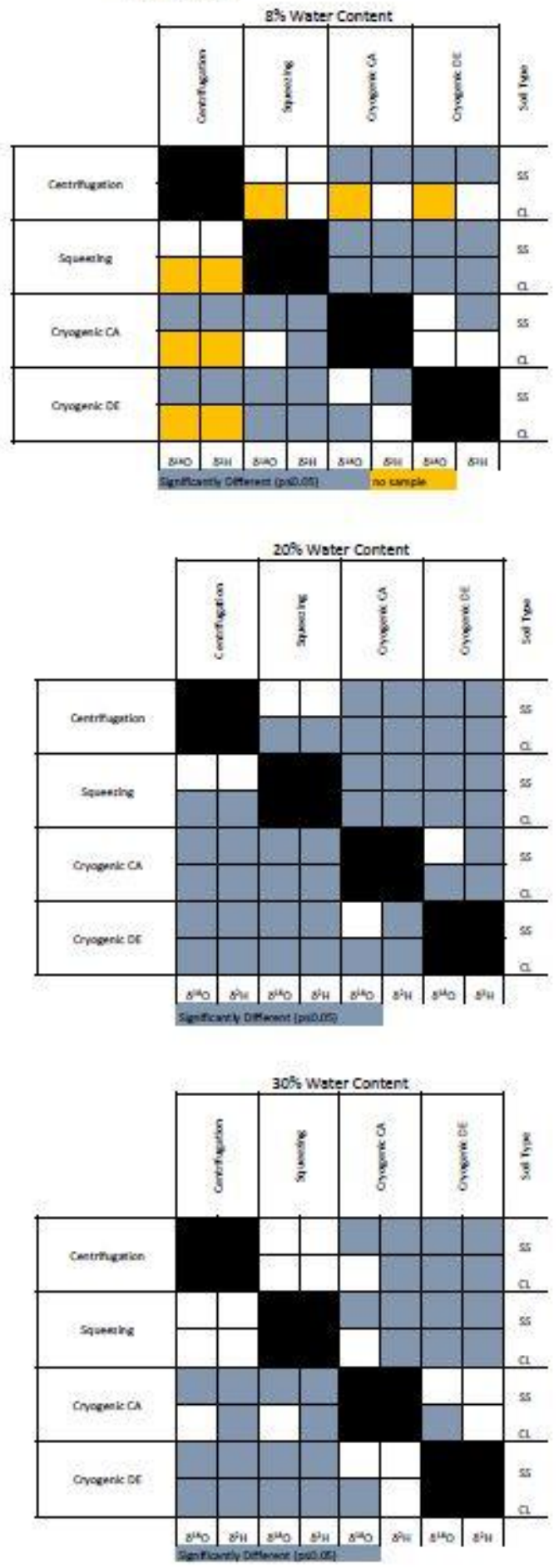

Figure 1. Compilation of statistical results for $\delta^{18} \mathrm{O}$ and $\delta^{2} \mathrm{H}$ of (a) OA-ICOS and (b) IRMS measurements from water extractions of silty sand and clayey loam.

This article is protected by copyright. All rights reserved. 


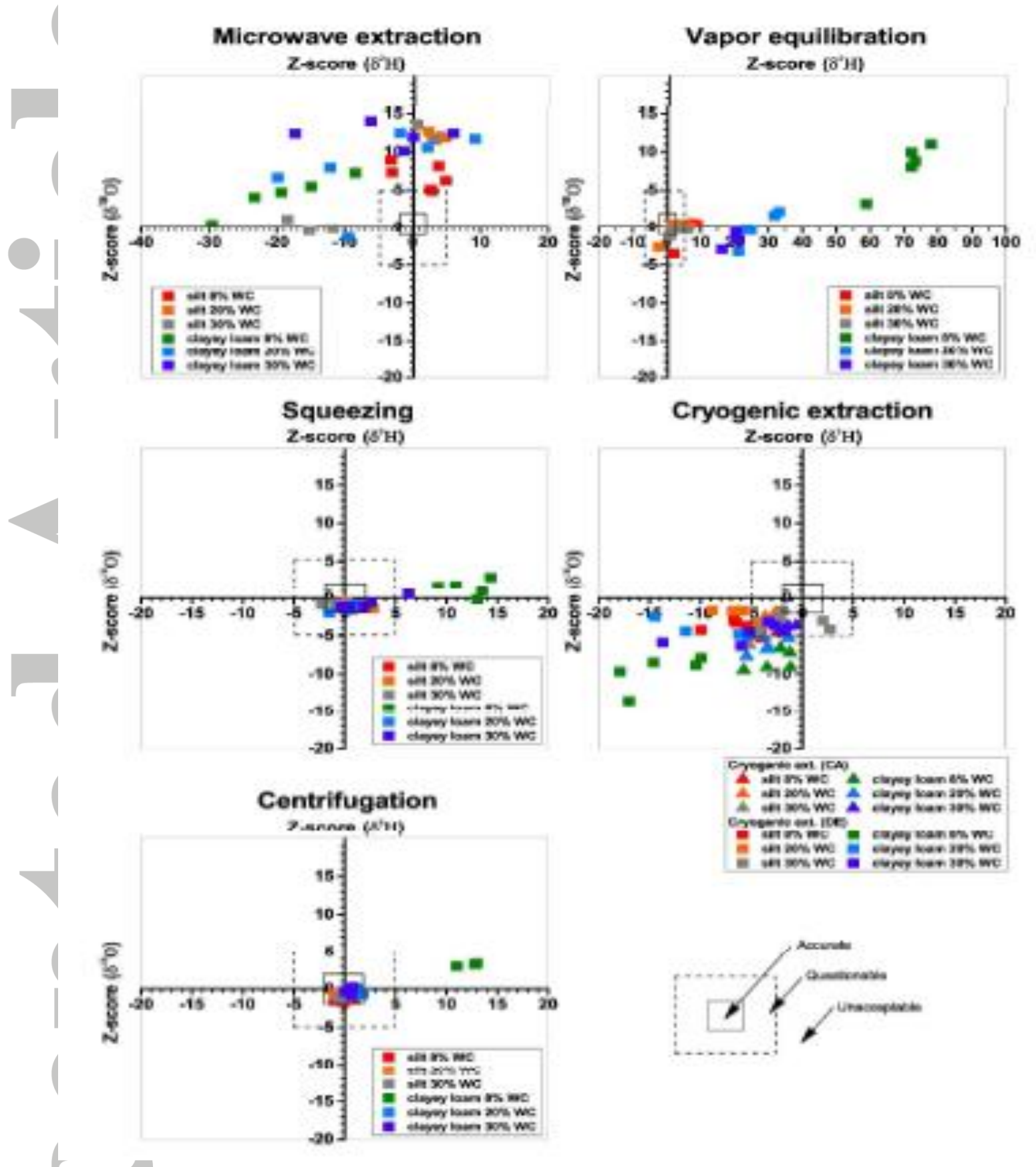

Figure 2. Performance cross plot of $\delta^{2} \mathrm{H}$ and $\delta^{18} \mathrm{O}$ Z-scores measured via OA-ICOS for all extraction methods, both soil types, and water contents (WC).

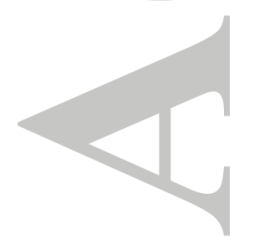

This article is protected by copyright. All rights reserved. 

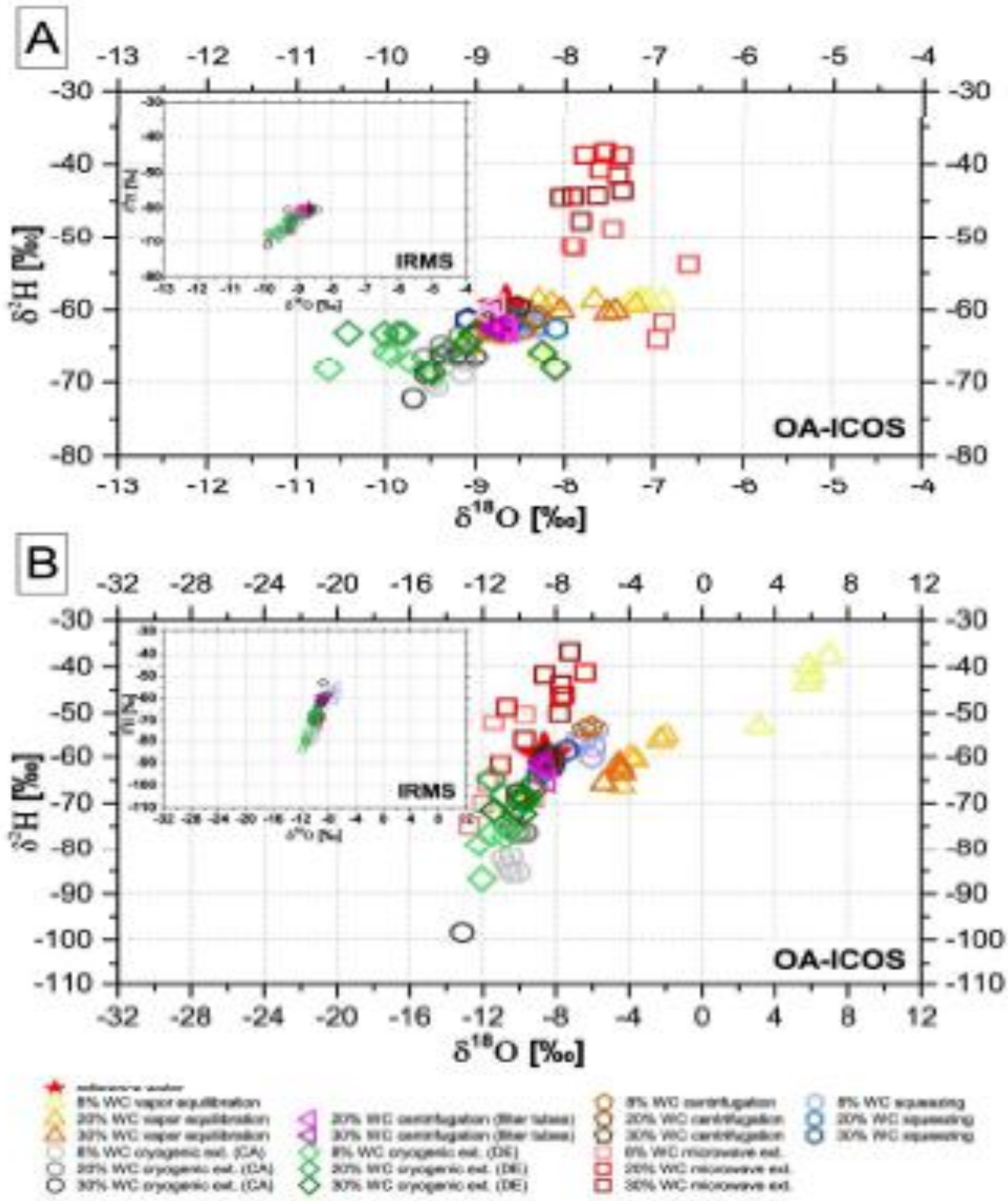

Figure 3. Dual isotope plots for silty sand (A) and clayey loam (B) water extracts of all methods and water contents (WC) in comparison to the reference water (red asterisk) for OAICOS and IRMS measurements (insets upper left).

This article is protected by copyright. All rights reserved. 